\title{
Hábitat sostenible. Adaptación y mitigación frente al cambio climático. Hacia los territorios resilientes
}

\section{Sustainable Habitat. Adaptation and mitigation against climate change. Towards the resilient territories}

\author{
DOI: $10.17981 /$ mod.arq.cuc.18.2.2018.03
}

Fecha de Envío: 28/08/2018 Fecha de Aceptación: 23/10/2018

Kevin Rafael Therán Nieto

ARKCO Semillero de Investigación - Universidad de la Costa (Colombia) ktheran1@cuc.edu.co

\author{
Lizeth Rodríguez Potes \\ Universidad del Atlantico (Colombia) \\ licirodriguez01@gmail.com
}

Para citar este artículo:

Therán, K. y Rodríguez, L. (2018). Hábitat sostenible. Adaptación y mitigación frente al cambio climático. Hacia los territorios resilientes. MODULO ARQUITECTURA-CUC, vol. 21, no. 1, pp. 63-96. DOI: 10.17981/mod.arq.cuc.18.2.2018.03

\section{Resumen}

La población mundial, en pleno siglo XXI, enfrenta su mayor desafío: el cambio climático. La sostenibilidad, la preservación, el desarrollo y la resiliencia estructuran el camino en la búsqueda de la adaptación y mitigación frente al cambio climático. Este texto académico e investigativo tiene por objetivo analizar los problemas generados por el cambio climático, así como, la búsqueda de alternativas para la adaptación y mitigación frente a este a partir de la organización de comunidades resilientes. El artículo aborda las causas y efectos del cambio climático a nivel mundial y, en especial, en la región americana del centro y sur, con particularidad en Colombia, y cómo las comunidades resilientes pueden lograr adaptarse y mitigar los efectos del cambio climático preservando la biodiversidad del planeta, cuidando de los recursos naturales y gestionando de forma eficiente las zonas urbanas y rurales.

Palabras clave: cambio climático, comunidades resilientes, sostenibilidad, hábitat, adaptación

\begin{abstract}
The world population, in the XXI century, faces its biggest challenge: climate change. Sustainability, preservation, development and resilience structure the way in the search for adaptation and mitigation against climate change. This academic and research text aims to analyze the problems generated by climate change, as well as the search for adaptation and mitigation against this from the organization of resilient communities. The article addresses the causes and effects of climate change worldwide and especially in the Central and South American region, with particularity in Colombia, and how resilient communities can adapt and mitigate the effects of climate change, preserving the biodiversity of the region planet, taking care of natural resources and efficiently managing urban and rural areas.
\end{abstract}

Keywords: Climate change, resilient communities, sustainability, habitat, adaptation. 


\section{INTRODUCCIÓN}

\section{Cambio climático. \\ La supervivencia en \\ el planeta Tierra}

La sostenibilidad, la preservación, el desarrollo y la resiliencia estructuran el camino en la búsqueda de la adaptación y mitigación frente al cambio climático. Este texto académico e investigativo tiene por objetivo analizar los problemas generados por el cambio climático, así como, la búsqueda de alternativas para la adaptación y mitigación frente a este a partir de la organización de comunidades resilientes. La población mundial, en pleno siglo XXI, enfrenta su mayor desafío. Con la industrialización y el desarrollo de nuevas tecnologías, se ha facilitado la dinámica cotidiana del ser humano y se han abierto posibilidades de cambio en muchos ámbitos, tales como la economía, la salud, la educación e incluso el desarrollo urbano de las grandes ciudades. Sin embargo, la situación mundial de esta centuria no puede ser comparada con sus predecesoras y no se hace esta excepción solamente por los logros obtenidos, sino por los múltiples problemas de índole social, ecológico-ambiental y, por si fuera poco, económico que viven las personas en las distintas regiones del planeta.

Según la Organización Mundial de la Salud (OMS), la mitad del mundo carece de acceso a servicios de salud y, con información del Banco Mundial, el acceso a buena educación, electricidad, agua segura y otros servicios fundamentales sigue estando fuera del alcance de muchas personas, a menudo por razones socioeconómicas, geográficas, étnicas y de género (OMS, 2017). Para todos es evidente que la Tierra se está "muriendo" y es inminente para el planeta la necesidad de obtener un cambio, puesto que el cambio climático es una realidad manifiesta. Una evidencia científica internacional abrumadora señala que desde 1750 el planeta está experimentando un calentamiento neto, y que durante el presente siglo continuará calentándose a consecuencia de las emisiones de gases de efecto invernadero (GEI) producidas por la acción humana, en particular, la procedente del consumo de petróleo y carbón. Este es, sin duda, el problema más grave en el campo ambiental y, según muchas autoridades, la mayor amenaza global en términos absolutos (Rodríguez y Mance, 2009). Lo anterior indica que el cambio climático es una "enfermedad" que viene aquejando a la humanidad desde hace más de dos siglos, pero considerablemente se ha visto en aumento en el último siglo, todo esto relacionado con el crecimiento de la población y las exageradas densidades poblacionales dentro de un área específicamente urbana. El cambio climático es definido como un cambio en el patrón del clima y los cambios relacionados en los océanos, las superficies terrestres y las capas de hielo, que se producen a lo largo de escalas de décadas o más (Australian Academy of Science, 2018). 
Hay múltiples causas que originan el cambio climático, aun así, para la Convención Mundial de Cambio Climático, el cambio climático es causa directa o indirecta de actividades humanas que alteran la composición de la atmósfera mundial, y que viene a añadirse a la variabilidad natural del clima observada durante periodos de tiempo comparables. Esto indica que la actividad humana, ya sea en sectores económicos y/o productivos, y en zonas industrializadas, tiene una grave repercusión en la variación del sistema climático mundial. Una de las tantas consecuencias humanas sobre el sistema climático son los gases de efecto invernadero (GEI) que pueden ser definidos como compuestos químicos en estado gaseoso, como el vapor de agua, el dióxido de carbono $\left(\mathrm{CO}_{2}\right)$, el metano $\left(\mathrm{CH}_{4}\right)$ y el óxido nitroso $\left(\mathrm{N}_{2} \mathrm{O}\right)$, que se acumulan en la atmósfera de la Tierra y que son capaces de absorber la radiación infrarroja del Sol y retener el calor en la atmósfera contribuyendo al efecto invernadero que intensifica sus efectos sobre el clima en la medida que aumentan (Ministerio de Medio Ambiente y Desarrollo Sostenible-Minambiente, 2018a). Hay que tener claro que el efecto invernadero mantiene una adecuada temperatura media global. Durante mucho tiempo han existido emisiones naturales de gases de efecto invernadero, pero el problema está en el aumento de estos gases en los últimos años. Los científicos conocen el efecto invernadero desde 1824, cuando Joseph Fourier calculó que la Tierra sería más fría si no hubiera atmósfera. Este efecto invernadero es lo que hace que el clima en la Tierra sea apto para la vida, sin él, la superficie de la Tierra sería unos 60 grados Fahrenheit más fría. En 1895, el químico suizo Svante Arrhenius descubrió que los humanos podrían aumentar el efecto invernadero produciendo dióxido de carbono, un gas de invernadero (National Geographic, 2010).

Los gases efecto invernadero son muestra del deterioro que la actividad del hombre le causa a la atmósfera. Para el Panel Intergubernamental sobre el Cambio Climático (IPCC), el cambio del clima, tal como se entiende en relación con las observaciones efectuadas, se debe a cambios internos del sistema climático o de la interacción entre sus componentes, o a cambios de forzamiento externo debidos a causas naturales o a actividades humanas. En general, no es posible determinar claramente en qué medida influye cada una de esas causas. En las proyecciones de cambio climático del IPCC se suele tener en cuenta únicamente la influencia ejercida por los aumentos antropógenos de los gases de efecto invernadero sobre el clima y por otros factores relacionados con los seres humanos (IPCC, 2007). De cierta forma, el desarrollo humano en la superficie terrestre ha tenido efectos negativos en el clima natural de cualquier región del planeta. Esto no quiere decir que los desarrollos tecnológicos e industriales son dañinos, sino que el mal uso y poco cuidado por parte del hombre, su falta de escrúpulos y, tal vez, de conciencia ecológica y ambiental para con las comunidades mundiales, ha provocado 


\section{Emisiones de gases de efecto invernadero por sector económico}

66

Producción eléctrica

y térmica

$25 \%$

AFOLU

$24 \%$

Edificios

$6,4 \%$

Transporte

$14 \%$

Total: $49 \mathrm{Gt} \mathrm{CO}$-eq

(2010)

Industria

$21 \%$

Otra energía

$9,6 \%$

\section{Emisiones directas de GEI}


un sinnúmero de problemas netamente climáticos, físico-naturales y de salud. Así, las emisiones antropogénicas totales de GEl pueden ser estudiadas de cinco sectores económicos como industria, transporte, edificaciones, AFOLU ${ }^{1}$, electricidad y/o energía (Fig. 1).

El rápido aumento de los gases de invernadero es un problema que está cambiando el clima tan rápido que algunos seres vivos no pueden adaptarse (National Geographic, 2010). Además, entre 1970 y 2004, los cambios en factores tales como el aumento del ingreso per cápita (un aumento del $77 \%$ ) y el crecimiento de la población (un aumento del 69\%) han favorecido el aumento de las emisiones de GEI. Estos han sido, en cierta medida, compensados por aumentos en la eficiencia y/o reducciones en la intensidad de carbono en la producción y el consumo, sin embargo, la tendencia mundial global todavía ha sido hacia grandes aumentos en las emisiones antropogénicas de GEI (ONU-Habitat, 2011). La biodiversidad y las comunidades del planeta se enfrentan a nuevos climas, abruptos por su variación indefinida. La vida en la Tierra está peligrando por el cambio climático: los cultivos no logran un desarrollo estable por las alteraciones climáticas, la fauna y flora es vulnerable ante las largas temporadas secas, la aglomeración de la población en las ciudades y la construcción no sostenible provocan

\footnotetext{
${ }^{1}$ Agricultura, el sector forestal y cambio de uso del
} suelo. las Ilamadas Islas de Calor Urbana (ICU)2, la deforestación de bosques reduce los beneficios de los árboles para el planeta, la contaminación del agua amenaza la supervivencia de especies acuáticas, la falta de interés para con los estuarios y ecosistemas primarios disminuye la reproducción de especies nativas y migratorias, el deshielo del permafrost peligra la vida en los polos, etc. Las mayores amenazas de supervivencia, resistencia y preservación causadas por el cambio climático las pueden enfrentar los biomas del planeta como los desiertos polares, las regiones biogeográficas polares de tundra, las tundras alpinas, las extensas regiones selváticas tropicales, la taiga, la estepa, los grandes desiertos y sabanas, los imperiosos bosques y las regiones mediterráneas.

Diversas entidades mundiales, como, por ejemplo, el Grupo Intergubernamental de Expertos sobre el Cambio Climático (IPCC), el Banco Mundial, la Organización de las Naciones Unidas (ONU) y la Organización Mundial de la Salud (OMS), entre otras, suman sus esfuerzos en la búsqueda de una solución para lograr la adaptación y mitigación frente al cambio climático. El cambio climático, las islas de calor urbana, la extinción de especies, la vulnerabilidad de la vida saludable y el bienestar de las comunidades en el planeta deben ser los puntos por solucionar para establecer el verdadero desarrollo sostenible.

\footnotetext{
${ }^{2}$ Una isla de calor urbana ocurre cuando una ciudad experimenta temperaturas mucho más cálidas que las áreas rurales cercanas (NASA, 2018).
} 
América Latina

(región de Centro y Suramérica), el cambio climático y factores ambientales

La región de América Central y América del Sur alberga ecosistemas únicos y tiene la mayor biodiversidad del planeta y una variedad de gradientes eco-climáticos (IPCC, 2014). Con la gran riqueza de fauna y flora a nivel mundial, la región central y del sur de América, se convierten en puntos ecosistémicos a nivel mundial. Estas presentan una gran variedad de biomas terrestres, desde selvas tropicales, sabanas, estepas, desiertos y grandes extensiones de bosques, que vuelven a estas dos regiones las más biodiversas. Además, existen países en estas regiones con ciertas peculiaridades en su conformación urbana y aglomeración poblacional. Pese a los climas cálidos y tropicales y un porcentaje alto de humedad, las regiones de América Central y América del Sur están altamente amenazadas por el cambio climático. Durante las últimas décadas, en América Latina se han observado importantes cambios en la precipitación y aumentos en la temperatura (Conde y Saldaña, 2007).

En el quinto reporte del IPCC de 2014, se establece un gráfico de los posibles cambios que se pueden presentar en la región latinoamericana del centro y sur en cuanto a temperatura y precipitación anual se refiere, todo esto visto desde un primer momento, que se refiere al principio del siglo $X X I$, y un segundo momento, que explica los posibles cambios para finales del mismo siglo (Fig. 2).

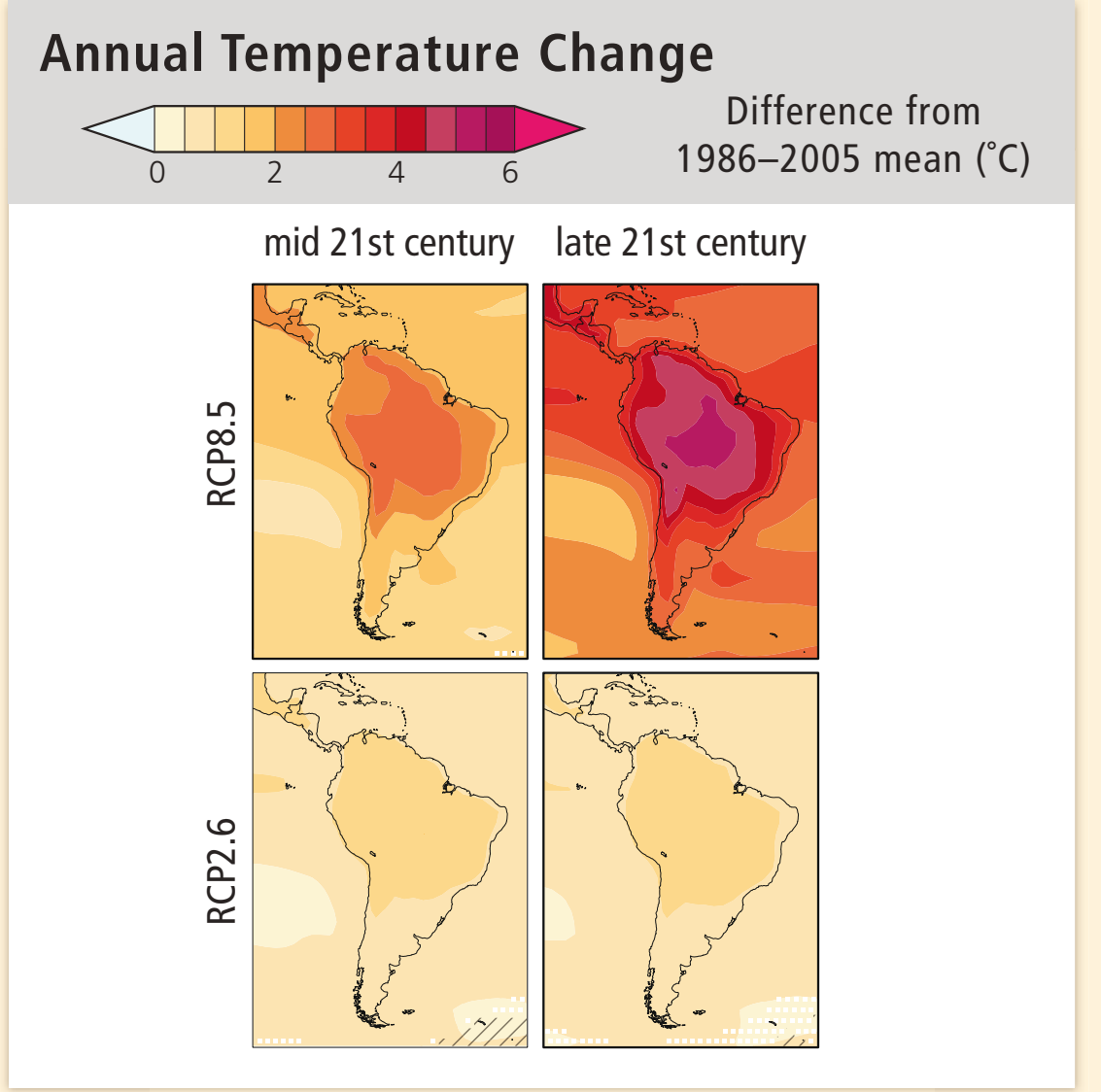

Solid Color

Very strong agreement

White Dots

Strong agreement

Fig. 2a. Cambios proyectados en la temperatura media anual. Proyecciones medias CMIP5 de modelos múltiples de cambios de temperatura promedio anuales.

Fuente: Magrin, Marengo, Boulanger, Buckeridge, Castellanos, Poveda, Scarano y Vicuña (2014). 


\section{Annual Precipitation Change}

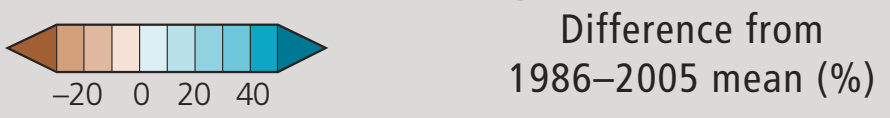

mid 21 st century late 21 st century
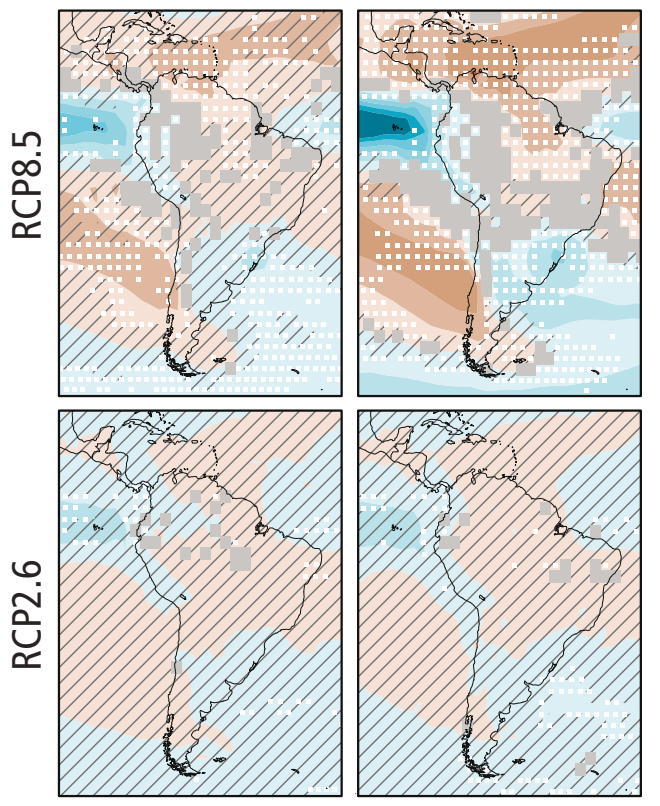

Gray

Divergent changes

\section{Diagonal Lines}

\section{Little or} no change

Fig. 2b. Cambios proyectados en la precipitación media anual. Proyecciones medias CMIP5 de modelos múltiples de cambios de temperatura promedio anuales.

Fuente: Magrin, Marengo, Boulanger, Buckeridge, Castellanos, Poveda, Scarano y Vicuña (2014).

En la región de América Central se presentará un calentamiento anual medio de $2,5^{\circ} \mathrm{C}$ y una reducción del 10\% en la precipitación durante el verano, mientras que, en América del Sur, se presentará un calentamiento medio de $4^{\circ} \mathrm{C}$, con una reducción de lluvia de hasta un $15 \%$ en las zonas tropicales, $y$, al este de los Andes, un aumento aproximado de un 15 a un 20\% (Magrin et al., 2014). Es preocupante las cifras entregadas: en las zonas tropicales de Suramérica las lluvias se verán reducidas, aunque en un mínimo porcentaje, pero el fenómeno de la Niña se volverá extenso lo que puede provocar sequías, pérdidas de cultivos y especies de flora, y llevar hasta el límite la supervivencia de la fauna tropical (Magrin et al., 2014). Por otro lado, en los Andes se presentará un aumento en las lluvias, lo que significa períodos más largos del fenómeno El Niño. Estos fenómenos del ciclo climático global se presentan en las regiones tropicales causando variación de las precipitaciones y temperaturas mensuales, y estos ciclos del sistema climático, en muchos casos, pueden durar hasta dos semestres.

Los riesgos que producen los efectos del cambio climático son inminentes: con el calentamiento global, los animales de las zonas polares sufren por el deshielo de glaciares; con la deforestación de manglares, el ciclo de limpieza y protección de cuerpos de agua es mínima; de igual manera, la acción del hombre con los procesos de industrialización y extracción de gas y petróleo, ocasiona la muerte de muchas especies animales y vegetales cuando se filtra parte del crudo o líquido contaminante a cualquier cuerpo de agua cercano. En las regiones de América Central y América del Sur, los países unen esfuerzos por preservar 
gran parte de la fauna y flora nativa o existente, además de contribuir al salvaguardo de comunidades indígenas que, lamentablemente, son las poblaciones más vulneradas por los procesos de desarrollo político-social y que, de cierta manera, no tienen forma de mantener en pie su legado ancestral. La reducción de las especies biológicas y los cambios ecosistémicos suponen un daño inmensurable para el bienestar humano. El agua, el alimento, la energía y la cohesión social son todos factores que peligran ante la destrucción inminente del planeta (Vogt, 2018). Según la Plataforma Intergubernamental Científico-normativa sobre Diversidad Biológica y Servicios Ecosistémicos (IPBES), para 2050 las poblaciones de especies en el continente americano se reducirían $40 \%$ debido, sobre todo, al cambio climático (IPBES, 2018). Mirando desde este punto, faltarían treinta y dos años para que gran parte de las especies de todo el continente desaparezcan. Aunque muchas organizaciones buscan preservar dichas especies, los cambios del sistema climático y del entorno paisajístico y natural donde viven han modificado los ciclos de reproducción y vida de muchos animales.

Entre 2005 y 2010, la región de Centroamérica y América del Sur ha perdido 38.300 $\mathrm{km}^{2}$ de bosques por año $(69 \%$ de la deforestación mundial) (Fig. 3).

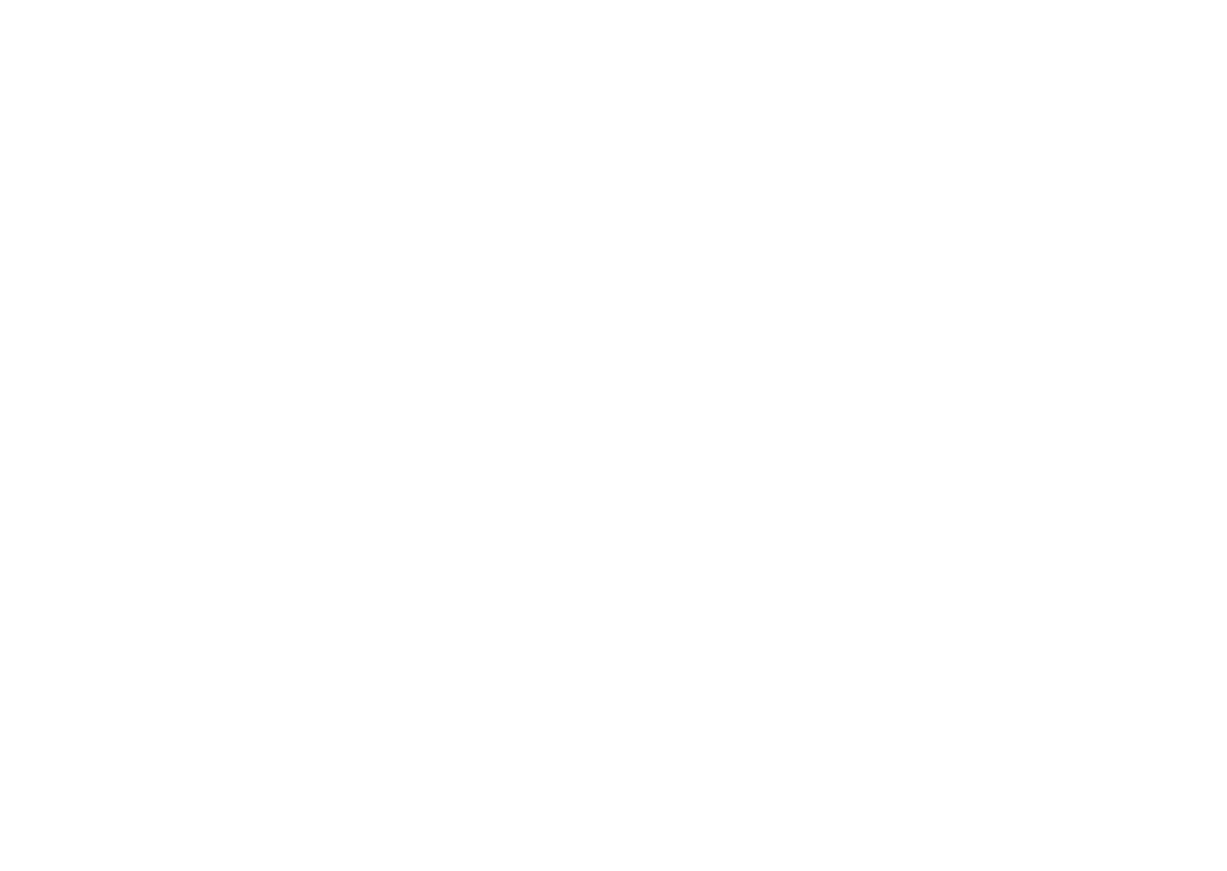

Fig. 3. Cambio en la cobertura forestal por año para países seleccionados en Centro y Suramérica (2005-2010). 
Los países con mayor deforestación en orden decreciente fueron Brasil, Bolivia, Venezuela, Argentina, Honduras, Nicaragua y Guatemala. Sin embargo, en algunos países, como Costa Rica, El Salvador, Panamá, Chile y Uruguay, la cobertura forestal mostró una leve tendencia a la recuperación (Magrin et al., 2014). Los porcentajes de deforestación en países como Brasil y Bolivia son considerables, entre 6000-6500 km² de zonas selváticas y/o bosques son deforestados. Consumido por las llamas de un reciente incendio, el Parque Nacional de la Chapada dos Veadeiros, en Brasil, sufre con el avance de la agricultura y la especulación inmobiliaria, pero su deforestación intenta ser revertida ahora mediante la recolección de semillas (EFE, 2018). Aspectos como la preservación de la flora por medio de recolección de semillas para luego ser plantadas y así esperar amplias zonas de bosques y selva son proyectos que revitalizan la tierra y las regiones. Por otro lado, países como Costa Rica, Chile y Uruguay le apuestan a la reforestación, aunque son porcentajes mínimos, alrededor de $500 \mathrm{~km}^{2}$, pero la pequeña acción debe conllevar fructuosos beneficios para esos países y el planeta entero. Se ha recibido ayuda internacional para prevenir la deforestación en la selva amazónica en las últimas décadas, tanto por sus altas tasas como por su rica biodiversidad (Magrin et al., 2014). La selva del Amazonas constituye un gran pulmón verde para el planeta, sin embargo, la deforestación de grandes regiones selváticas amazónicas cambia la forma de vida de comunidades indígenas, fauna y flora presente. Los árboles tienen efectos positivos a nivel urbano pero su efecto a nivel selvático y/o rural es mayor de acuerdo con su proporción (Rodríguez, Hanrot, Dabat e Izard, 2013) (Rodríguez, Hanrot, Dabat e Izard, 2012) (Rodríguez, 2010). La vegetación es el sistema respiratorio del planeta: remueve el dióxido de carbono y otros contaminantes, regenera el oxígeno de la atmósfera, restablece los niveles de humedad y atrapa el polvo del ambiente (García y Fuentes, 2005).

La degradación de la tierra también es un proceso importante que compromete áreas muy extensas de Centroamérica y Suramérica muy rápidamente. Según datos del proyecto Global Assessment of Land Degradation and Improvement (GLADA) del Global Environment Facility (GEF), las áreas degradadas adicionales alcanzaron el $16,4 \%$ del total territorio de Paraguay, el $15,3 \%$ de Perú, y el $14,2 \%$ de Ecuador para el período 1982-2002. En Centroamérica, Guatemala muestra la mayor proporción de tierras degradadas, actualmente es el 58,9\% del territorio del país, seguido por Honduras $(38,4 \%)$ y Costa Rica (29,5\%); solo El Salvador muestra una reversión del proceso de degradación de la tierra, probablemente debido a una menor explotación de la tierra luego de intensos procesos migratorios internacionales (Magrin et al., 2014). El cambio de uso del suelo, que en su mayoría se pasa de suelo rural a urbano, va afectando las zonas de vegetación existente; el nuevo uso de la tierra afecta la calidad de esta, reduciéndose los nutrientes presentes, el nacimiento de nuevos árboles y el mínimo crecimiento o muerte de flora ya existente. 
El desarrollo humano debería reducirse o equilibrarse de acuerdo con la acción de los recursos naturales, pues, en ocasiones, no se permite la regeneración de la tierra.

América Latina y el Caribe albergan una asombrosa cantidad de biodiversidad y riqueza natural, recursos que constituyen los cimientos de muchas de sus economías. Sin embargo, la región enfrenta algunos desafíos importantes, por ejemplo, más del $80 \%$ de la población vive en ciudades donde la contaminación del aire y el transporte ineficiente causan problemas de salud y pérdidas de productividad. Aunque la región es responsable de alrededor del $10 \%$ de las emisiones globales de gases de efecto invernadero, es altamente vulnerable al efecto del cambio climático, el cual generó un costo de alrededor de US\$100.000 millones en 2015 (ONU, s.f.). Es importante resaltar que esta región latinoamericana produce el diezmo de las emisiones de gas de efecto invernadero a nivel mundial y, paradójicamente, son los más propensos a sufrir por el cambio climático.

Por otra parte, los países desarrollados, o del primer mundo, tienen los mayores registros de emisiones de GEl per cápita en los últimos años: Australia de 20 a 25, China y Japón de 5 a 10, Rusia de 10 a 15 y Estados Unidos de América de 15 a 20 (Programa de las Naciones Unidas para el AmbientePNUMA, 2015). Las ciudades de la región central y del sur de América tienen claros problemas de planeación urbana, pocas son las que le apuestan a un desarrollo sostenible en temas de movilidad y construcción; además, la forma de vida menos saludable de los ciudadanos, la falta de conciencia ecológica y el uso excesivo de sistemas de climatización no prevén una mejora de las consecuencias del calentamiento global en las pequeñas y grandes poblaciones. Hay cambios en las condiciones ambientales en períodos cortos de tiempo que amenazan la supervivencia de los ecosistemas y las especies, y, por lo tanto, la forma de vida de las sociedades dependientes de ellos (Conde y Saldaña, 2007).

La sociedad latinoamericana necesita entender las consecuencias del cambio climático. Son las personas, las únicas capaces de revertir ciertos efectos del cambio del clima; de promover acciones de protección medioambiental; de valorar la riqueza en biodiversidad que tienen los países centro y suramericanos; de preservar los recursos naturales, como el agua, para evitar la contaminación, el derroche y poco cuidado de los mismos; de construir sosteniblemente; y de fomentar espacios para el bienestar social; pero sobre todo, los gobiernos deben establecer políticas de economía social y buena alimentación. La ONU Ambiente trabaja en América Latina y el Caribe con los gobiernos, la sociedad civil y el sector privado para abordar las prioridades del cambio climático y lograr una mayor comprensión de las causas y los impactos del cambio climático en la economía y el bienestar humano (ONU, s.f.).

Los efectos de las emisiones de gases de efecto invernadero son reales y están cada vez más presentes. Todavía se pueden mitigar los cambios peligrosos en los sistemas climáticos: si setransforman los sistemas de energía basados en carbono y se empiezan a implementar programas 
de adaptación con fondos adecuados, se podrían evitar desastres y migraciones a escalas sin precedentes (ONU, s.f.). Al analizar lo expuesto por la ONU, se pueden identificar tres aspectos fundamentales en la reversión del calentamiento global: el primero, transformar los sistemas de energía que se usan en las pequeñas y grandes edificaciones en climas como los que se presentan en América Central y América del Sur, se usan excesivamente sistemas de climatización para generar confort térmico dentro de las edificaciones, pero el costo y gasto energético generado es grande; segundo, los cambios en el sistema climático resultan en fenómenos naturales como ciclones, tormentas tropicales y huracanes, y las regiones más afectadas son la centroamericana y del Caribe, estos desastres naturales destruyen zonas urbanizadas enteras y reducen al mínimo la calidad de vida de las personas que, a pesar de tener conocimiento en los riesgos que corren por los fenómenos naturales, no tienen programas de protección contra estos o de ayuda para ser resilientes ante los mismos; el tercero, son las migraciones a gran escala, ejemplo de esto es la situación de miles de venezolanos a nivel regional, quienes al no tener una situación estable económica y de bienestar humano en su país, deciden migrar a países "hermanos" como Colombia, Ecuador, Perú o Brasil, sin embargo, a estos nuevos países de llegada se le suma otro problemas social, el desempleo y la gran necesidad de bienestar económico y salud de ellos. A pesar de que el cambio climático supone afectar aspectos ambientales, ecológicos y urbanos, también el desarrollo social, económico y el bienestar humano se ven afectados. Empero es importante lograr el crecimiento económico sustentable para prevenir futuros incrementos en las emisiones de los GEl, cumplir con la reducción de emisiones en la región no prevendrá que esta no sufra los impactos del cambio climático, no obstante, las dramáticas evidencias de pérdidas debidas a los desastres naturales y de las proyecciones de los impactos negativos debidos al cambio climático (Conde y Saldaña, 2007).

Las actividades agrícolas son importantes para el desarrollo económico de las comunidades, sin embargo, las multinacionales o empresas nacionales deforestan grandes extensiones de suelo vegetal y arborizado para la siembra, y lo que debería suponer un crecimiento económico, adversamente, se vuelve un efecto del calentamiento global. Esto no quiere decir, explícitamente, que la actividad agrícola es mala para las comunidades, por el contrario, la agricultura rural y urbana de las comunidades en escalas considerables y equilibradas al medio ambiente generan grandes beneficios para el desarrollo social-económico y reducción de efectos del cambio climático, pero la actividad agrícola a gran escala e industrial es la que afecta al medio ambiente al deforestar la cobertura vegetal. Casi un tercio de las emisiones de gases de efecto invernadero se deben a la actividad agrícola, y aquí se incluye la generación de dióxido de carbono por la labranza, el uso de fertilizantes que aumentan la presencia del óxido nitroso y el metano que surge por la actividad pecuaria (Chuet-Missé, 2017). 


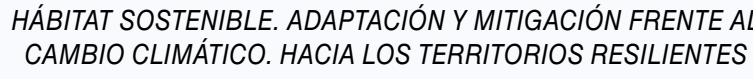

El uso de la tierra y el cambio de la cobertura del suelo son factores claves del cambio ambiental regional en América Central y América del Sur. Los ecosistemas naturales se ven afectados por cambio climático de la tierra, la deforestación, la degradación de la tierra y perdida de biodiversidad se atribuyen, principalmente, al aumento de la agricultura extensiva para las actividades tradicionales de exportación y los cultivos de bioenergia (Magrin et al., 2014). Las comunidades cercanas a las grandes zonas de protección ambiental buscan salvaguardar el medioambiente pero las políticas de estado les conceden permiso a las grandes empresas para 74 tomar campo en esos terrenos.

En el informe del 2014 del IPCC acerca del cambio climático, en la parte $B$ de aspectos regionales sobre los impactos, la adaptación y la vulnerabilidad, grupo de estudio para America Centra (CA) y America del Sur (SA) resume los cambios observados en el clima y otros factores medioambientales subdividiendo la región en zonas de análisis y resultados. El resumen se realiza con el fin de entender tanto las problemáticas que se presentan en la región latinoamericana del centro y del sur como las fortalezas para la resilencia de las comunidades para con el cambio climatico. La región las mayores riquezas en biodiversidad a nivel mundial y continental antagónicamente presenta los mayores riesgos ambientales y climáticos (Fig. 4).

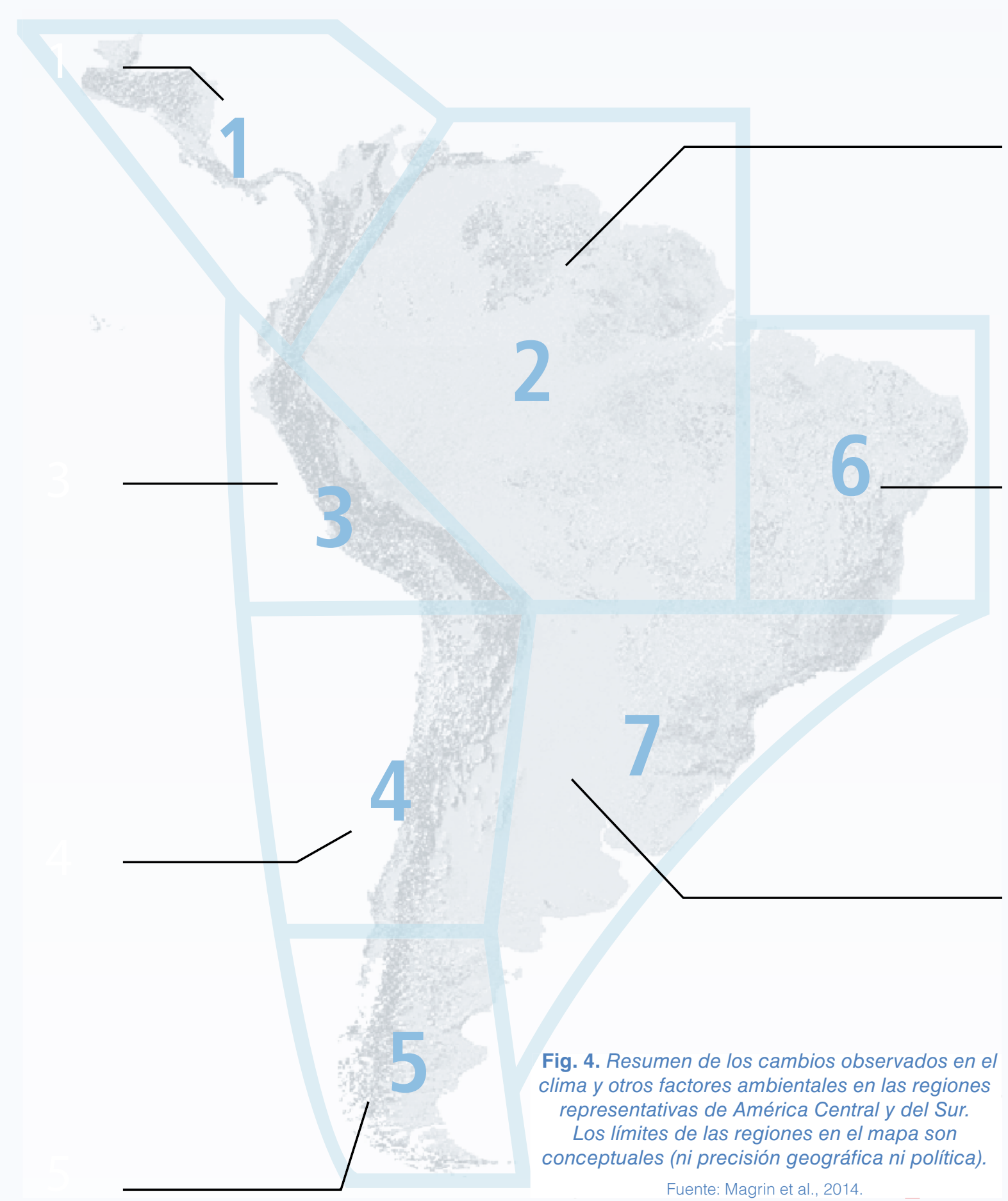

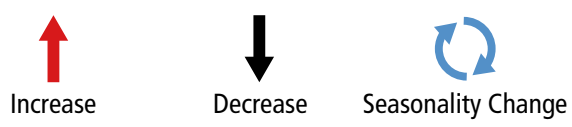 lemperature Glacier 
La primera zona de estudio es Centroamérica (CA) y el noroccidente de América del Sur (NSA): aquí se observa un aumento en la temperatura media producto del cambio climático; reducción y variación en los regímenes anuales de precipitaciones; disminución de los caudales de ríos y cuerpos de agua; también se observó un aumento en la deforestación $y$, por consiguiente, mínimas zonas forestadas. Por último, se percibe un aumento de plagas como insectos que aumentan los índices de enfermedades. La segunda zona corresponde a la Amazonía (AMA): en esta subregión, la temperatura aumentó; el régimen de precipitación anual presentó variaciones, en ciertas temporadas aumentó y en otras disminuyó; el caudal de los ríos se movió de acuerdo con las temporadas de lluvias; disminuyeron las zonas forestadas; la actividad agrícola aumentó al igual que las plagas. La tercera zona pertenece a los Andes Tropicales (TAnd): en este fragmento regional la temperatura aumentó; el nivel de nieve en el territorio disminuyó; el caudal en los cuerpos de agua varió y las plagas aumentaron. La cuarta zona corresponde a los Andes centrales (CAnd): la temperatura en esta subregión aumentó; las lluvias disminuyeron al igual que el nivel de nieve en los glaciares tropicales; de igual forma, el caudal de los ríos y los cuerpos de agua disminuyeron y/o presentaron variación, además, aumentaron las zonas forestadas. La quinta zona es la Patagonia (PAT): aquí se observa un aumento en la temperatura y, por consiguiente, disminución de los niveles de nieve en los glaciares tropicales. La sexta zona es el noreste de Brasil (NE): se presenta aumento en la temperatura; disminución de los ciclos de precipitaciones anuales y cobertura forestal; y aumento en la actividad agrícola, lo que acarrea el crecimiento de plagas. La séptima y última zona corresponde al suroriente de América del Sur (SESA): resultando en un aumento de la temperatura; aumento en los regímenes de precipitaciones anuales; disminución de la cobertura forestal; y aumento en las actividades agrícolas y plagas. Al comparar todos los datos por subregiones, existen aspectos preocupantes como:

- Aumento en la temperatura

- Variación en los regímenes de precipitación anual

- Disminución de la cobertura forestal

- Aumento de las plagas

- Aumento de la actividad agrícola (en tres subregiones)

Este último aspecto de actividad agrícola puede aumentar la seguridad alimentaria cuando la escala de siembra y producción es adecuada y sostenible, sin embargo, como fue expuesto anteriormente, puede ser perjudicial a escala industrial para la cantidad de cobertura forestal y, por ende, riesgoso para el medio ambiente. En condiciones de cambio climático, las actividades agrícolas probablemente serán severamente 
afectadas en América Latina y el Caribe con disminuciones importantes en los rendimientos. Es probable que las plagas amplíen su territorio y los procesos de degradación de suelos aumenten. Las sequías, las inundaciones, las ondas de calor y otros eventos climáticos extremos afectarán de manera significativa estas actividades agrícolas, poniendo en riesgo la seguridad alimentaria (Conde y Saldaña, 2007).

Los resultados finales del IPCC para América Central y América del Sur son:

- Cambios en la variabilidad del caudal del río Amazonas durante las últimas 2 décadas, tendencias positivas robustas en el flujo de las cuencas de la cuenca del Río de la Plata y aumento de la sequedad en la mayoría de las cuencas en la costa oeste de Sudamérica durante los últimos 50 años

- Reducción de glaciares tropicales y campos de hielo en los Andes tropicales y extra-tropicales durante la segunda mitad del siglo $X X$, que puede atribuirse a un aumento de la temperatura

- Aumento del rendimiento agrícola en el suroriente de Suramérica y cambio en la zonificación agrícola (expansión significativa de las áreas agrícolas, principalmente en regiones climáticamente marginales)

- Aumento de la frecuencia y la extensión de la fiebre del dengue, la fiebre amarilla y la malaria
Colombia: ¿la extinción de la biodiversidad, riquezas naturales y peligro de las comunidades?

Colombia, uno de los países del mundo con mayor biodiversidad y riquezas naturales enfrenta su mayor reto en siglos de lucha, guerra y búsqueda de la paz. A pesar de que los problemas sociales en el país son de gran cuidado y pronta solución, las inminentes consecuencias del calentamiento global no quedan atrás. Para el año 2040, 119 municipios del país estarán en muy alto riesgo por el cambio climático, al igual que los departamentos de San Andrés, Vaupés, Amazonas y Guainía serán los más afectados. Los 20 departamentos con mayor riesgo por cambio climático albergan el $57 \%$ de la población del país y representan el $69 \%$ del Producto Interno Bruto (PIB) (Medioambiente, 2017a). Los departamentos que serán más afectados se encuentran en las regiones Caribe y Amazónica, donde la cobertura vegetal es amplia al igual que la biodiversidad de fauna y flora, pero las comunidades se encuentran vulnerables. El Instituto de Hidrología, Meteorología y Estudios Ambientales (IDEAM) y el Programa de las Naciones Unidas para el Desarrollo (PNUD) (2017) entregaron en el mes de septiembre del año pasado la Tercera Comunicación Nacional de Cambio Climático, donde se expone que el país es responsable del $0,42 \%$ de las emisiones de gases de efecto invernadero (GEI) en 
el mundo. Además, especifican que, en nueve departamentos del país, sumando el Distrito Capital (Antioquia, Meta, Caquetá, Valle del Cauca, Santander, Cundinamarca, Casanare, Boyacá, Guaviare y Bogotá), se concentran el $59 \%$ de las emisiones de GEI. Los sectores que generan mayores emisiones de GEI son los relacionados con los cambios en el uso del suelo (62\%), el transporte (11\%) y las industrias manufactureras (11\%) (Medioambiente, 2017). De esta manera, Colombia se encuentra dentro del $20 \%$ de los países responsables de las emisiones de GEI, siendo el quinto país en América Latina y el 40 en el mundo que emite más emisiones, algo preocupante para un país en vía de desarrollo (Pardo, 2017).

Fig. 5. Sierra Nevada del Cocuy, uno de los ecosistemas más frágiles del país por el cambio climático.

Fuente: Lizarazo, 2017.

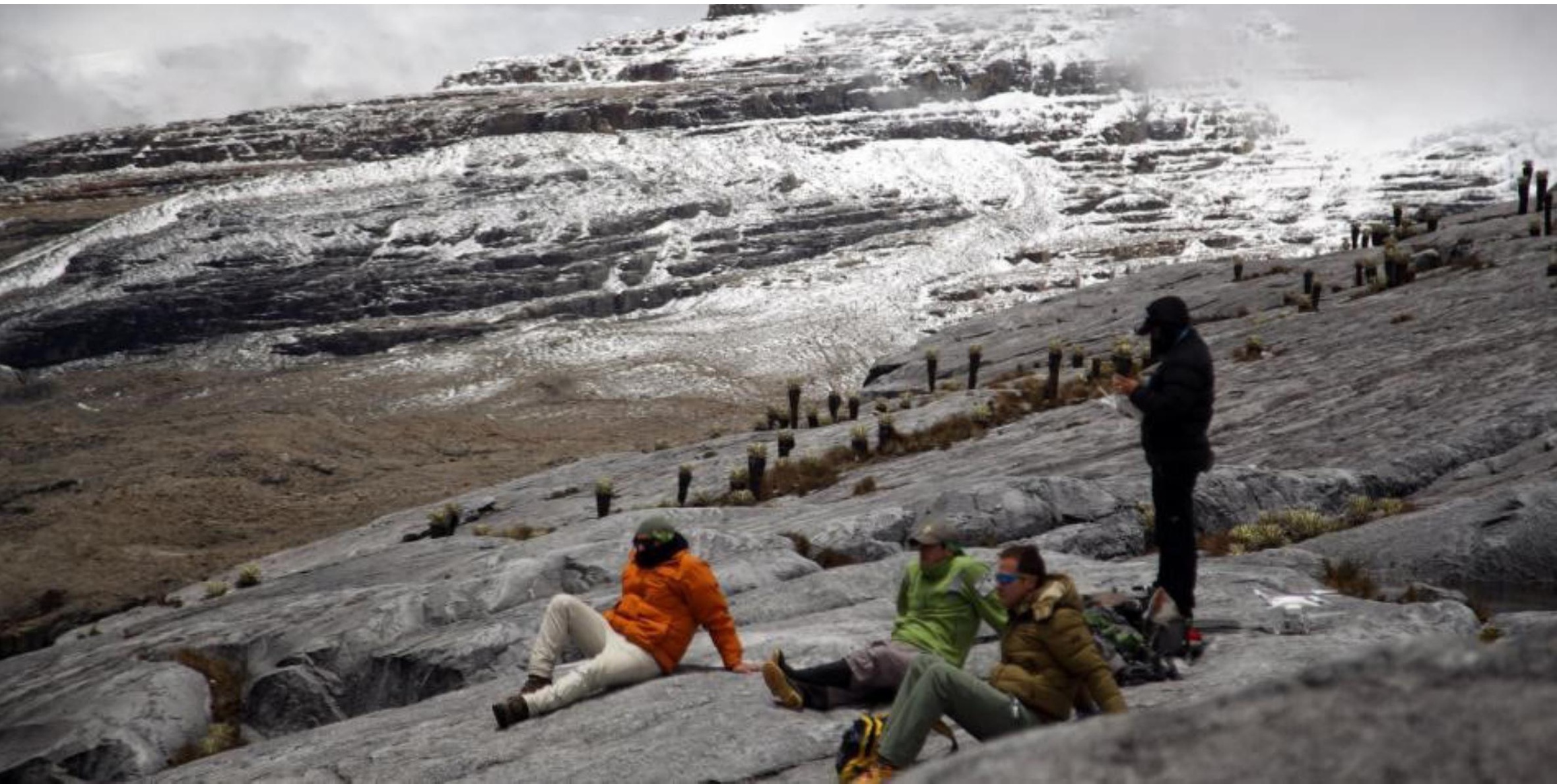


La belleza de los ecosistemas de Colombia es única; alberga una de las mayores cantidades de especies de flores y aves en el mundo. Lamentablemente, la amenaza hacia estos crece cada día. Así como muchos países del mundo, Colombia tiene planes para la adaptación y mitigación frente al cambio climático. Desde el Gobierno y Minambiente, se gestionan planes políticos y ambientales encaminados a la sostenibilidad del país. Para lograr los objetivos, el Gobierno plantea cinco estrategias territoriales y trasversales: desarrollo urbano, desarrollo rural, manejo y conservación de ecosistemas y los servicios que ofrece, desarrollo minero energético bajo en carbono y desarrollo de infraestructura estratégica (Medioambiente, 2017b).

Los efectos del cambio climático en Colombia, según el Plan Nacional de Adaptación al Cambio Climático (Minambiente, 2016), se pueden clasificar por Nodos Regionales de Cambio Climático-NRCC ${ }^{3}$ :

1. Amazonía. En el piedemonte, al occidente de los departamentos de Caquetá y Putumayo, se proyecta un menor incremento (entre 0 y $0,5^{\circ} \mathrm{C}$ ) de la temperatura promedio respecto al resto de la región donde será de

\footnotetext{
${ }^{3}$ Los Nodos Regionales de Cambio Climático -NRCC, son instancias regionales que operan como grupos de coordinación técnica. Son consideradas por las entidades coordinadoras del PNACC como la principal ruta de enlace nación-regiones, y desde su conformación cuentan con el apoyo técnico de las mismas (Minambiente, 2016).
}

entre 0,74 y $0,81^{\circ} \mathrm{C}$. En cuanto a lluvia promedio anual, en el área suroriental (Amazonas, Vaupés y parte de Caquetá), se proyecta una disminución de entre el 5,5\% y el 20\%. En tanto que para el resto de la región se proyecta una menor reducción de lluvia e incluso para el piedemonte de Caquetá y Putumayo se proyectan incrementos de entre el 10\% y el 30\%. La porción de la región natural de la Amazonía, ubicada en la macrocuenca Orinoquia, seguirá una tendencia similar a la del resto de esa macrocuenca, con lluvias promedio similares a las del periodo de referencia y áreas pequeñas de reducción de entre el $10 \%$ y el $19 \%$.

2. Andes (región andina). La temperatura promedio aumentará en toda la región, si bien en diferente magnitud por efecto de la altitud. Los incrementos serán menores en las partes más altas de las montañas, entre 0 y $0,8^{\circ} \mathrm{C}$; y más altos en los valles de los ríos Atrato, Magdalena y Cauca, entre 0,81 y $1,2^{\circ} \mathrm{C}$. En cuanto a la lluvia promedio anual, en general, se espera un aumento, con valores hasta $20 \%$ mayores a los de referencia, salvo pequeñas excepciones. Entre estas se destacan el nororiente de Norte de Santander con reducciones de hasta un $40 \%$, y el nororiente de Antioquia, que pertenece a un área más amplia de la macrocuenca MagdalenaCauca, donde la reducción será de entre un $10 \%$ y un $30 \%$. 
3. Caribe. La temperatura media anual se incrementará gradualmente en toda la región. El cambio será menor en los pisos altitudinales más altos de la Sierra Nevada de Santa Marta y estribaciones de la cordillera de los Andes: entre 0,1 y $0,8^{\circ} \mathrm{C}$. En áreas más bajas, la temperatura promedio llegará a ser hasta $1,2^{\circ} \mathrm{C}$ más alta. En cuanto a la lluvia, el Caribe es la región del país donde se esperan las mayores reducciones. San Andrés y Providencia, Magdalena, Bolívar y Guajira serán los departamentos con los cambios más significativos.

4. Orinoquía. La temperatura media anual se incrementará entre 0,67 y $0,94^{\circ} \mathrm{C}$, con menores cambios en la subregión del piedemonte. En cuanto a la lluvia, no se proyectan grandes variaciones con respecto a los valores históricos de referencia, si bien cabe tener precaución con las variaciones a lo largo del año, pues los escenarios sólo indican la tendencia promedio anual y no informan sobre eventos extremos.

5. Pacífico. La temperatura aumentará en mayor medida sobre el área litoral de la costa Pacífica, y en menor, sobre la cordillera de los Andes. Los incrementos estarán en el rango de 0,67 a $0,9^{\circ} \mathrm{C}$. La lluvia promedio anual será igual o mayor a los promedios del periodo de referencia. Los incrementos se esperan en áreas montañosas de los Andes occidentales con valores de hasta un 16\% más altos. Cabe mencionar que el Litoral Pacífico es actualmente la región más húmeda del país.
La tarea no es nada fácil, pero los esfuerzos por salvaguardar la integridad natural y ecosistémica del país son válidos, sin embargo, hay puntos inconclusos en la búsqueda del desarrollo sostenible.

\section{La inefable adaptación y mitigación frente al cambio climático: la resiliencia de las comunidades}

Antes de concluir el tema anteriormente descrito, es importante exponer algunas pautas de resiliencia frente a los efectos del cambio climático. Si bien es cierto que los efectos del cambio climático se presentarán en todo el planeta, hay ciertas regiones donde los efectos serán más inminentes, tales son los casos de los polos y las regiones ecuatoriales. Con el fin de ilustrar la magnitud del esfuerzo requerido, Pacala y Socolow (2004) se preguntaron qué se necesitaría hacer en los próximos cincuenta años con cada una de las tecnologías disponibles para reducir la emisión de gases de efecto invernadero un $14,28 \%$ de la cantidad necesaria para que la temperatura no exceda los dos grados centígrados (Rodríguez y Mance, 2009). A continuación, se exponen quince alternativas para estabilizar el clima (Pacala y Socolow, 2004, p. 968-972): 


\section{Alternativas de eficiencia}

1. Doblar la eficiencia de 2000 millones de carros de 48 a 96 kilómetros por galón.

2. Decrecer la distancia viajada por carro a la mitad: 8000 kilómetros por año.

3. Reducir a un cuarto las emisiones actuales de carbono asociado con la existencia de las residencias y edificios comerciales.

4. Incrementar la eficiencia de generación de electricidad basada en el carbón en un $50 \%$ con relación a la actual.

\section{Alternativas de descarbonización de la electricidad}

1. Reemplazar $1400 \mathrm{GW}$ de plantas termoeléctricas basadas en carbón por plantas potenciadas por gas.

2. Capturar y almacenar las emisiones de 800 GW basadas en carbón o 1600 GW de plantas basadas en gas.

3. Triplicar la capacidad actual de producción de energía nuclear para reemplazar termoeléctricas basadas en combustibles fósiles.

4. Incrementar la capacidad actual de generación de electricidad de origen eólico en 50 veces para sustituir plantas termoeléctricas basadas en carbón. Esto implica instalar 2'000.000 de molinos de viento que ocuparían 30'000.000 de hectáreas, continentales o marítimas.

5. Multiplicar por 700 la capacidad actual de electricidad solar para sustituir la producida por termoeléctricas basadas en carbón.

\section{Alternativas de descarbonización del combustible}

1. Capturar y almacenar el COQ en las plantas productoras de hidrógeno, que producen 400 Mt de hidrógeno por año, lo cual depende de la construcción de muchas más plantas productoras.

2. Capturar y almacenar el $\mathrm{CO}_{2}$ subproducto de la operación de 180 plantas productoras de 34 millones de barriles diarios de combustibles sintéticos producidos a partir de combustibles fósiles: carbón, gas natural o biomasa.

3. Producir hidrógeno para carros a partir de energía eólica en vez de combustibles fósiles, lo cual requiere de 4 millones de molinos de $1 \mathrm{MW}$.

4. Incrementar la producción de etanol en 50 veces mediante la creación de plantaciones para la generación de biomasa, lo cual requeriría un sexto de la tierra agrícola. 
Alternativas de bosques y suelos

1. Eliminar la deforestación tropical y quintuplicar las plantaciones existentes de bosques en suelos deforestados.

2. Adoptar sistemas de labranza de conservación en todos los suelos del mundo.

De esta forma, en un plazo de cincuenta años la suma de estas quince alternativas estabilizaría las emisiones de gases de efecto invernadero a un nivel cuyos impactos serían manejables (Pacala y Socolow, 2004).

Comunidades resilientes. La resiliencia es la capacidad adaptiva de un componente ante cualquier situación adversa que limite o amenace su supervivencia, por consiguiente, una comunidad resiliente al cambio climático es aquella que agrupa sus esfuerzos por adaptarse y mitigar las consecuencias del cambio climático, transformado las condiciones del entorno a su favor y reduciendo al mínimo el índice de vulnerabilidad. Por otra parte, según el IPCC (2007), la resiliencia climática es definida como la capacidad de un sistema ecológico o social de absorber perturbaciones manteniendo la misma estructura y formas de funcionamiento básicas, la capacidad de auto-organización y la capacidad de adaptarse al estrés y los cambios. La resiliencia de las comunidades frente al cambio climático, desde este enfoque investigativo, tiene varios componentes: componente ambiental y/o ecosistémico, componente urbano y sostenibilidad del hábitat.
Las comunidades resilientes en el componente ambiental y/o ecosistémico deberían tener como objetivos el aumento de la cobertura forestal y la preservación de ecosistemas (biomas terrestres) y biodiversidad. La reducción de bosques, los sistemas ecosistémicos primarios, los afluentes o cuerpos de agua y la fauna y flora sufren y sufrirán las mayores consecuencias del cambio climático. La agricultura expansiva y la industria maderera ha deforestado gran cantidad de los bosques del mundo, amenazando la supervivencia de las especies animales. Habitamos un planeta excelso y lleno de peculiares formas de vida; existen regiones en el planeta que aún conservan la belleza de millones de años de constante evolución, Nueva Zelanda es uno de esos. Desde que Nueva Zelanda se separó del supercontinente, ha evolucionado una flora y fauna únicas para dar lugar a una tierra llena de plantas y criaturas interesantes. Especies endémicas de ese territorio, como el loro kakapo, el kiwi y el takahe, son únicas en el mundo y cuya permanencia se encuentra en peligro (Pure New Zealand, s.f.). Si seguimos en el camino del crecimiento industrial, desconsiderado en zonas boscosas, los efectos del cambio climático irán en aumento, la temperatura media global aumentará considerablemente, muchas especies animales se extinguirán y la vida en el campo sufrirá drásticos cambios. Pero no solo el cambio climático, la acción del hombre también repercute en la pérdida de biodiversidad. Por ejemplo, en el período de colonización de Nueva Zelanda, los colonos cazaron aves y trajeron depredadores, incluso ratas 
Resiliencia urbana y sostenibilidad del hábitat. Es importante, antes de abordar el tema de resiliencia urbana y sostenibilidad del hábitat, dejar claro el concepto de sostenibilidad y su relación con el desarrollo urbano. ICLEI ${ }^{4}$ en 1994 expone un concepto considerablemente lógico y claro acerca de la sostenibilidad:

La sostenibilidad supone la mejora del nivel de vida conforme a la capacidad de carga del medio ambiente natural y urbano. La sostenibilidad implica que el consumo de recursos no supere la capacidad de la naturaleza para reemplazarlos. Aborda el mantenimiento de la biodiversidad, la salud y la calidad de vida en el futuro. La sostenibilidad es un equilibrio dinámico, y un camino en el cual las metas se van articulando a medio y largo plazo, en base a los condicionantes intrínsecos de cada localidad (ICLEI, 1994)

Entonces, la sostenibilidad del hábitat 5 , entendiendo el hábitat desde un concepto urbano, es el equilibrio y mejora del nivel de vida de los individuos que habitan en un medio urbano, salvaguardando los recursos de la comunidad y, sobre todo, mediante la implementación de estrategias que busquen un alto índice de la calidad de vida, confort humano y correcta planificación territorial donde la prioridad sea la preservación y conti-

${ }^{4}$ International Council for Local Environmental Initiatives: Local Governments for the Sustainability

${ }^{5}$ En ecología se refiere al lugar con las condiciones apropiadas para que viva un organismo, especie o comunidad animal o vegetal. (RAE, s.f.) En urbanismo es el espacio construido donde vive el hombre. nuidad de la biodiversidad presente en el entorno urbano, el control de las actividades humanas que contaminan e influyen en el cambio climático, la revitalización de los espacios y la disminución de los asentamientos humanos informales cuyas condiciones ambientales, tipologías y materiales de viviendas no contribuyan a la salubridad o sustentabilidad de estos.

Las comunidades resilientes empiezan con la búsqueda del desarrollo urbano sostenible. La sostenibilidad urbana se convierte en uno de los caminos más importantes en la capacidad resiliente de una comunidad para la adaptación y mitigación frente al cambio climático. Con este enfoque investigativo y basado en el aprendizaje de la arquitectura y el urbanismo, algunos elementos que ayudan a las ciudades a adaptarse a los efectos del cambio climático, desde la gestión y planificación territorial, son:

- La morfología urbana y edificabilidad

- Movilidad urbana sostenible

- Mayor índice de cobertura vegetal en la ciudad

- Eficiencia energética en las edificaciones y políticas de uso de energías renovables

- Asentamientos urbanos humanos formales

- Aplicación de modelos de agricultura y silvicultura urbana

- Reutilización y manejo adecuado de residuos sólidos y líquidos 
- Mitigación de los efectos de las islas de calor urbana (ICU)

- Control del uso del suelo y disminución de la contaminación ambiental desde los usos residenciales e industriales

- Diseño de espacios urbanos con parámetros bioclimáticos y medioambientales

El desarrollo sostenible se ha convertido en el eje clave para la ordenación territorial, la política y la gestión de los recursos y del espacio urbano (Higueras, 2009). Las consecuencias del cambio climático corresponden a un aumento de la incidencia de las catástrofes que tienen consecuencias directas e indirectas sobre la organización y el funcionamiento de la ciudad (Bertoux y González, 2015). Como se ha mencionado anteriormente, las zonas urbanas sufren y sufrirán los mayores efectos y consecuencias del cambio climático. Por ejemplo, el aumento del consumo de energía en las ciudades, las zonas urbanas a nivel mundial, el clima y las dotaciones naturales de un área urbana son factores importantes que configuran el patrón de uso de energía. Una ciudad ubicada en latitudes altas, por ejemplo, podría consumir más energía para calentar sus edificios y casas que una situada en los trópicos; y, por el contrario, un centro urbano ubicado en los trópicos podría consumir más energía para el aire acondicionado. Por lo tanto, el cambio climático afectará el comportamiento de consumo de energía en muchas áreas urbanas del mundo (ONU-Habitat, 2011).
La resiliencia urbana es la capacidad de una ciudad expuesta a amenazas para resistir, absorber, adaptarse y recuperarse de sus efectos de manera oportuna y eficiente, lo que incluye la preservación y restauración de sus estructuras y funciones básicas (Schuschny, 2014). Por esto, las comunidades deben conocer cuál es su vulnerabilidad, en qué se está fallando, qué les perjudica y amenaza su estabilidad. En este caso, la vulnerabilidad de las comunidades es el cambio climático. El conocimiento de la vulnerabilidad de un sistema urbano no significa directamente el establecimiento de sus condiciones de resiliencia. Si bien la resiliencia depende en parte de la vulnerabilidad de un territorio, el establecimiento de sus condiciones depende de otros factores (Bertoux y González, 2015).

Siguiendo este camino, una ciudad resiliente es aquella que evalúa, planea y actúa para preparar y responder a todo tipo de obstáculos, ya sean repentinos o lentos de origen, esperados o inesperados. De esta forma, las ciudades estarán mejor preparadas para proteger y mejorar la vida de sus habitantes, para asegurar avances en el desarrollo, para fomentar un entorno en el cual se pueda invertir y promover el cambio positivo (ONU-Habitat, 2017). Si se planteara, hipotéticamente, cambios en la dinámica urbana, como disminución en la disponibilidad de alimentos a falta de buenas cosechas que se vean afectadas por cambios en el clima o sensaciones térmicas muy elevadas por la poca arborización en los espacios urbanos, todos los individuos de una comunidad estarían afectados. 
Sin embargo, si antes de que estos hechos pudieran suceder la comunidad empieza a implementar modelos de agricultura urbana, es decir, cada unidad o conjunto residencial decidiera crear huertos urbanos para cultivar gran parte de sus alimentos, aumentar la siembra de árboles en espacios urbanos o construir edificaciones con jardines y zonas verdes internas, se podría empezar con el cambio, y, con todo esto, la sensación térmica elevada disminuiría favorablemente produciendo confort térmico, las personas tendrían acceso propio a parte de sus alimentos, además, de generarse efectos positivos en otras áreas, como la reducción del consumo de energía en los hogares y edificaciones y el equilibrio del gasto económico en las viviendas. La resiliencia urbana y la sostenibilidad del hábitat se convierten en un camino hacia el éxito de la vida en el futuro. Hoy, los seres humanos tienen en sus manos, tal vez, la mayor decisión de todas: asegurar su supervivencia en el planeta Tierra.

Es apremiante la necesidad de construir nuevas herramientas y planteamientos que den poder a los gobiernos locales y a los ciudadanos, así como que incrementen su capacidad para afrontar nuevos desafíos protegiendo mejor a los humanos y a los activos económicos y naturales de nuestros pueblos y ciudades (ONU-Habitat, 2017).

Fig. 7. Maíz, fríjol, patata y trigo se ven afectados por el calentamiento global.

Fuente: Chuet-Missé, 2017.

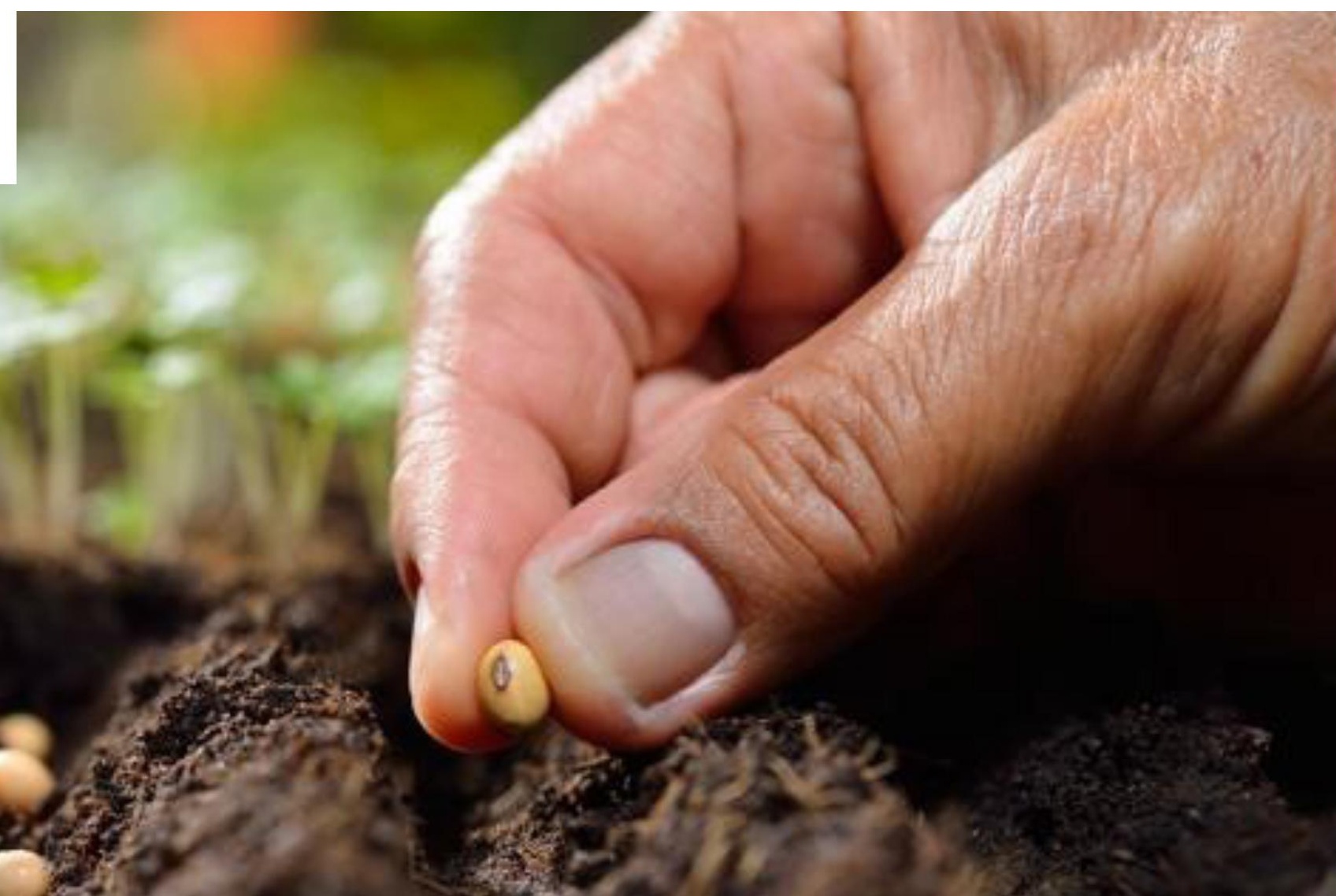


Seguridad alimentaria en las comunidades resilientes. Uno de los principales retos que trae el cambio climático es la seguridad alimentaria del mundo (Gómez, 2018). Los cambios drásticos en el clima pueden provocar pérdidas de cosechas y, por consiguiente, reducir la seguridad alimentaria. La seguridad alimentaria entra como un componente fundamental en los ejes adaptativos de una comunidad resiliente. Los sistemas alimentarios resilientes al clima son robustos frente a perturbaciones climáticas, se adaptan y reorganizan para responder al estrés y se recuperan rápidamente de eventos extremos (International Institute for Sustainable Development, IISD, 2013).

Para lograr la resistencia de los cultivos a los efectos del cambio climático, diversas investigaciones han desarrollado "súper semillas". La creación de nuevos tipos de semilla, usando los genes de sus parientes salvajes o de otros tipos "domesticados", evita que sequías, pestes o inundaciones ocasionen crisis de hambruna (ChuetMissé, 2017). Esto lo hacen con el objetivo de asegurar el bienestar alimentario de las personas ante posibles desastres o pérdidas de cultivos ocasionados por las variaciones del clima. Por ejemplo, el fríjol, el maíz, la patata o el trigo se han visto muy comprometidos con el aumento de la temperatura global (Chuet-Missé, 2017) (Fig. 7).
Por otro lado, el marco de evaluación del IOTWS 6 (2004), citado por IISD (2013), identifica ocho elementos de resiliencia, aplicables en cuanto a seguridad alimentaria y gestión del riesgo y prevención de desastres por los cambios del clima. Las siguientes son las definiciones de los ocho elementos:

1. Gobernanza: los dirigentes pueden proporcionar e implementar marcos legales para ofrecer servicios básicos a las comunidades y crear condiciones para mejorar la resiliencia.

2. Sociedad y economía: diversificación de los medios de vida para reducir la dependencia de los recursos costeros.

3. Gestión de los recursos costeros: se gestionan los recursos de modo que se conserven los servicios y medios de vida del ecosistema, y se implementan iniciativas para reducir los riesgos que provienen de las amenazas costeras.

4. Uso de la tierra y diseño estructural: la planificación y los diseños estructurales abarcan metas ambientales, económicas y comunitarias para reducir los riesgos que provienen de las amenazas.

5. Conocimiento de los riesgos: las autoridades encargadas de la gestión de desastres y los miembros de la comunidad son conscientes de los riesgos y amenazas; y se utiliza la información sobre los riesgos para la toma de decisiones.

${ }^{6}$ Indian Ocean Tsunami Warning System Program 
6. Alertas y evacuación: la comunidad recibe notificaciones y alertas de las amenazas costeras, las personas están dispuestas a evacuar la zona y disponen de la infraestructura adecuada para evacuaciones seguras.

7. Respuesta a situaciones de emergencia: se han establecido y se mantienen mecanismos y redes para responder rápidamente en caso de desastres y emergencias, tanto en el ámbito comunitario como en el municipal y el nacional.

8. Recuperación de los desastres: la recuperación debe incluir planes a corto y largo plazo para volver a desarrollar las zonas y promover los medios de vida. Esto se hace por medio de actividades anteriores a los episodios peligrosos con el fin de acelerar la recuperación en casos de desastres, y también por medio de la participación de la comunidad en los procesos de recuperación, incluso aquellos que afectan a las personas más vulnerables.

El cambio climático significará alteraciones cada vez mayores a los ecosistemas y las obras de infraestructura debido a eventos climáticos graves más frecuentes y extremos, un aumento de la variabilidad del clima y cambios graduales pero fundamentales, como un aumento del nivel del mar o sequías. Estos, sin duda, afectarán los sistemas alimentarios de muchos modos aún no previstos (IISD, 2013). Pero, cada esfuerzo es útil y necesario. En la resiliencia de una comunidad existen 5 factores de análisis de la seguridad alimentaria (IISD, 2013):

- Utilización de alimentos de un hogar

- Acceso a los alimentos

- Disponibilidad de los alimentos

- Recursos y servicios de apoyo

- Organizaciones y políticas de apoyo

Estos factores, apoyados en la comunidad, el sector público y privado, regularían los efectos del cambio climático en las formas de cultivos y alimentación de una comunidad, aumentando la capacidad de resiliencia y reducción de la vulnerabilidad. Tanto la seguridad alimentaria como la resiliencia climática son complejas. Ambas son propiedades emergentes del sistema alimentario, que son consecuencia de la interacción de muchos factores dinámicos de modos que no admiten una proyección lineal sencilla. A fin de brindar orientación práctica a los encargados de tomar decisiones a nivel comunitario o nacional, se debe empezar por desarrollar marcos conceptuales que expliquen cómo funcionan la seguridad alimentaria y la resiliencia climática en el seno de los sistemas alimentarios complejos (IISD, 2013). 
Modelos de ciudades resilientes: Casos a nivel mundial. Algunas ciudades alrededor del planeta han gestionado y puesto en marcha proyectos y programas para constituir una ciudad resiliente. En este caso, mencionaremos varias ciudades del mundo que, mediante estrategias de desarrollo sostenible (transporte y movilidad, agricultura, sistemas de energía alternativos, construcción y seguridad de vivienda, etc.), han impulsado la resiliencia de su territorio frente a los efectos del cambio climático:

- Barcelona, España: para contrarrestar la difícil situación de desempleo y falta de vivienda y promover el desarrollo sostenible, algunos funcionarios de la ciudad crearon equipos de resiliencia que promovían el uso de energías renovables, la reducción del uso de combustibles, el fomento al empleo y el transporte público e igualdad social, convirtiendo a Barcelona, poco a poco, en una ciudad de vanguardia (López, 2016). El Ayuntamiento de Barcelona sigue dando pasos innovadores para aumentar su resiliencia urbana, esta vez a través de un taller de múltiples socios sobre su próxima capacidad de recuperación (UN Habitat y UNISDR, 2018).

- Quito, Ecuador: a través del proyecto Agrupar, el municipio de Quito impulsa la práctica de la agricultura urbana en el Distrito, además de contribuir con la seguridad y soberanía alimentaria, aportar al mejoramiento de los ingresos de sus participantes, generar ahorro por el consumo de la producción propia.
Asimismo, por su naturaleza integradora de actividades agrícolas, pecuarias, de comercialización de excedentes, procesamiento de alimentos, intercambio solidario, gestión ambiental y aporte a la agroecología urbana, representa una importante estrategia de cohesión social (Conquito, 2017).

\section{Comunidades resilientes en Colombia.}

Colombia está implementando un Programa de Resiliencia (2017-2020), con el apoyo de la Organización de las Naciones Unidas para la Alimentación y la Agricultura (FAO), como compromiso por los acuerdos de paz y la resiliencia en el país. Las comunidades resilientes en Colombia, según la FAO (2017) y el Programa de Resiliencia, buscan la mejora del sector agropecuario, la gestión del riesgo y la paz y protección de las comunidades. Tiene dos ejes:

1. Modelo de recuperación rápida de la producción agropecuaria y de generación de resiliencia para comunidades rurales vulnerables: en este eje, la resiliencia se basa en la seguridad alimentaria y protección de las comunidades rurales vulnerables.

2. Gestión del riesgo integral del riesgo: este abarca la consolidación de la institucionalidad de la gestión del riesgo agroclimático, la adaptación al cambio climático del sector agropecuario y la aplicación en diferentes niveles territoriales con una visión global de resiliencia (FAO Colombia, 2017). 
Todo lo anterior está relacionado con las comunidades rurales y la actividad agrícola y pecuaria. A pesar de ello, es pertinente que las ciudades y/o zonas urbanas en Colombia entren en la senda de la resiliencia urbana y busquen métodos de adaptación y mitigación frente al cambio climático. Colombia es un país con abundante biodiversidad, multiculturalidad y regiones con distintos pisos térmicos y características naturales. Durante los ocho últimos años, el Gobierno nacional ha desarrollado un conjunto de acciones estratégicas frente a los desafíos que impone la adaptación y mitigación al cambio climático en el país. Muestra de ello son desarrollos normativos como la Política Nacional de Cambio Climático y otros instrumentos para la gestión y medición que vienen articulando distintas entidades, sectores y entes territoriales a nivel nacional (Minambiente, 2018b).

El Plan Nacional de Adaptación al Cambio Climático (2016) expone varias líneas de acción prioritarias para la adaptación al cambio climático en Colombia. Estas líneas de acción pueden ser tomadas como las pautas para la resiliencia en las comunidades colombianas. Las líneas de acción son emprendimientos encaminados hacia la adaptación, considerados como puntos de partida para el diseño e implementación de medidas de adaptación a desarrollarse de acuerdo con los contextos, los conocimientos y los consensos específicos de los territorios y sectores (Minambiente, 2016). A continuación, se mencionarán las líneas de acción más relevantes del PNACC (Minambiente, 2016) en el desarrollo de comunidades resilientes en Colombia:
- Incorporación de la variabilidad y cambio climático en los instrumentos de planificación del Estado

- Desarrollo de proyectos de inversión resilientes: adaptación sectorial al cambio climático que orienten los proyectos de inversión públicos y privados

- Gestión de los impactos del cambio climático sobre la biodiversidad y la oferta de servicios ecosistémicos

- Producción agropecuaria y seguridad alimentaria adaptadas al cambio climático

- Reducción prospectiva de riesgos en infraestructuras básicas (transporte, vivienda, sector minero y energético)

- Crecimiento verde de hábitats humanos: sistema de ciudades resilientes

El sistema de ciudades resilientes en Colombia, abordando las zonas urbanas, semiurbanas y rurales, deben incorporar mecanismos para el desarrollo de la resiliencia basados en la sostenibilidad del hábitat humano, la protección de cultivos y cosechas, la prevención y gestión del riesgo, la implementación y uso de energías alternativas, la construcción de edificaciones sostenibles, los planes de ordenamiento territorial que tengan en cuenta la adaptación al cambio climático y la reducción de la huella de carbono. Tal vez es complejo abordar el tema de la resiliencia al cambio climático, sin embargo, se hace necesario en cuanto a los distintos fenómenos que se presentan 
por la variabilidad del clima, el aumento de la temperatura global, la pérdida de glaciares y la polución que afectan la salud, el bienestar, la seguridad y el confort de una persona.

Para finalizar este apartado se hace necesario mencionar lo siguiente:

Estamos a tiempo de reconducir los modelos de intervención, gestión y planificación de las ciudades, solo hace falta transformar nuestro ejercicio profesional, nuestras dinámicas empresariales, sociales y capitalistas, nuestros procesos académicos de formación, los modos de interacción ciudadana, nuestra actividad vecinal y nuestra visión de desarrollo, entre muchas otras cosas, hacía una línea de acción más sostenible, pero sobre todo más sustentable en el tiempo, que sea respetuosa con el medio ambiente, más participativa y mucho menos egoísta; eso seguramente se verá reflejado desde los distintos sectores de la sociedad (público, privado y tercer sector) que guían la gestión de la ciudad (Rodríguez y Padilla, 2018).

\section{Conclusión}

La adaptación y mitigación frente al cambio climático es un asunto que le compete a cada individuo del planeta. La resiliencia a esta problemática puede lograrse en las pequeñas y grandes comunidades de la Tierra. Desde las poblaciones más alejadas de las zonas urbanas hasta las grandes ciudades y metrópolis, la sostenibilidad y resiliencia se hacen esenciales en la lucha contra los desastres, vulnerabilidades y desafíos a los que se enfrentan. El cambio climático ha creado un nuevo paradigma de lo vulnerable que es la vida en el mundo. La fragilidad del hombre es mucho más notoria cuando se hacen presente las fuerzas de la naturaleza (huracanes, tormentas, deslizamientos de tierra, terremotos, etc.). Existen múltiples alternativas para enfrentar los efectos negativos del cambio climático, siendo las comunidades resilientes, desde este punto de vista, uno de los más efectivos.

Tratar de resiliencia significa que se está pasando por una situación crítica o amenazadora, también simboliza la resistencia, cambio y transformación del entorno situacional. Las comunidades resilientes transforman las situaciones adversas, implementan herramientas y modelos de gestión basados en la sostenibilidad y desarrollo urbano/rural porque no solamente el término comunidades resilientes hace referencia a zonas netamente urbanas, sino que incluye a las zonas rurales, pequeños asentamientos humanos que viven en entornos más naturales donde no existe un departamento para la prevención y gestión del riesgo, ya que, de igual manera, esas comunidades que viven en entornos rurales sufren con el cambio climático. Así, las comunidades resilientes en la búsqueda por la adaptación y mitigación frente al cambio climático innovan en estrategias de planificación territorial, uso y conservación de los recursos naturales; preservación de la biodiversidad; creación de prototipos de agricultura sostenible; construcción verde o sustentable; reducción del consumo y/o gasto energético; y reforestación y aumento de la cobertura vegetal. 
Con todo esto, hay que añadir que la resiliencia al cambio climático tiene un componente social. La actuación de los individuos de una comunidad, como un todo y no como unidades independientes, permiten la capacidad resiliente de una zona. La resiliencia de cualquier comunidad frente a los efectos del cambio climático, buscando la adaptación y mitigación a este, debe procurar la salud, bienestar, seguridad y confort de los individuos, preservando la biodiversidad, reduciendo los puntos vulnerables y riesgos, y estando preparados ante cualquier emergencia por el clima. Las comunidades en zonas urbanas o rurales tienen que entender la necesidad de tomar medidas y acciones preventivas ante las consecuencias del cambio climático. La resiliencia se convierte en el principal camino en la sostenibilidad y adaptación. Los seres humanos deben interiorizar que están dejando un legado a las próximas generaciones: un planeta en riesgo a causa de los efectos del cambio climático.

\section{REFERENCIAS}

Australian Academy of Science. (2018). What is climate change? Recuperado de https://www.science.org.au/ learning/general-audience/sciencebooklets-0/science-climate-change/1what-climate-change

Bertoux, L. y González, D. (2015). Vulnerabilidad y resiliencia urbana frente al cambio climático: el caso de la zona metropolitana de Guadalajara, México. URBANO, 24-31.
Chuet-Missé, J. (Febrero 28, 2017). Las súper semillas que resisten al cambio climático. La Vanguardia. [CAMBIO CLIMÁTICO]. Recuperado de https://www.lavanguardia.com/ natural/20170228/42358632446/semillas-cambio-climatico.html

Conde, C. y Saldaña, S. (2007). Cambio climático en América Latina y el Caribe: Impactos, vulnerabilidad y adaptación. Revista Ambiente y Desarrollo de CIPMA, 23(2). 23-30.

Conquito. Agencia de promoción económica. (Mayo 9, 2017). Quito como ejemplo de resiliencia para el mundo en el Foro Ciudades Resilientes. Recuperado de http://www.conquito.org.ec/quito-comoejemplo-de-resiliencia-para-el-mundoen-el-foro-ciudades-resilientes/

EFE. (Marzo 28, 2018). Semillas contra la deforestación: reto de parques nacionales en Brasil. El Tiempo. [Vida]. Recuperado de http://www.eltiempo. com/vida/medio-ambiente/proyectode-semillas-contra-la-deforestacionen-brasil-197654

FAO Colombia. (2017). Programa de Resiliencia 2017-2020. Roma: FAO COLOMBIA.

García, J. y Fuentes, V. (2005). Viento y Arquitectura. El viento como factor de diseño arquitectónico. México, D.F.: Trillas.

Gómez, S. (Febrero 14, 2018). Cultivos resistentes a los cambios de clima. Recuperado de https://latinamericanpost.com/ es/19645-cultivos-resistentes-a-loscambios-de-clima 
Higueras, E. (2009). El reto de la ciudad habitable y sostenible. Pamplona: DAPP Publicaciones Jurídicas.

IDEAM-PNUD. (2017). Tercera comunicación nacional de Colombia. Recuperado de http://documentacion.ideam. gov.co/openbiblio/bvirtual/023732/ RESUMEN_EJECUTIVO_TCNCC_ COLOMBIA.pdf

ICLEI. (1994). Guía europea para la planificación de las Agendas 21 locales en Local Agenda 21. Recuperado de http://www.iclei.org

International Institute for Sustainable Development, IISD. (2013). Resiliencia climática y seguridad. Un marco para la planificación y el monitoreo. Winnipeg, Manitoba: The International Institute for Sustainable Development. Recuperado de https://www.iisd.org/sites/ default/files/publications/adaptation_CREFSCA_es.pdf

IPBES. (2018). IPBES: América Latina perderá $15 \%$ de flora y fauna hasta 2050. Recuerado de https://www. dw.com/es/ipbes-américa-latinaperderá-15-de-flora-y-fauna-hasta2050/a-43111188

IPCC. (2007). Cambio climático 2007: Informe de síntesis. Contribución de los Grupos de trabajo I, II y III al Cuarto Informe de evaluación del Grupo Intergubernamental de Expertos sobre el Cambio Climático. Ginebra: IPCC.
IPCC. (2014). Cambio climático 2014: Impactos, adaptación y vulnerabilidadParte B: Aspectos Regionales. Climate Change 2014, Mitigation of Climate Change (Contribución del Grupo de trabajo III al quinto informe de evaluación del Grupo Intergubernamental de Expertos sobre el Cambio Climático). Nueva York: Cambridge University Press.

Lizarazo, L. (Junio 13, 2017). Estos son los planes de Colombia para enfrentar el cambio climático. El Tiempo. [Vida]. Recuperado de https://www.eltiempo. com/vida/medio-ambiente/politica-decolombia-para-enfrentar-el-cambioclimatico-98710

López, M. (2016). ¿Qué es una ciudad resiliente? Y 8 ejemplos. Recuperado de https://www.expoknews.com/que-esuna-ciudad-resiliente-y-8-ejemplos/

Magrin, G., Marengo, J., Boulanger, J., Buckeridge, M., Castellanos, E., Poveda, G., Scarano, F. y Vicuña, S. (2014). Central and South America. In: Climate Change 2014: Impacts, Adaptation, and Vulnerability. Part B: Regional Aspects. Contribution of Working Group II to the Fifth Assessment Report of the Intergovernmental Panel on Climate Change. [V. Barros, C. Field, D. Dokken, M. Mastrandrea, K. Mach, T. Bilir, M. Chatterjee, K. Ebi, Y. Estrada, R. Genova, B. Girma, E. Kissel, A.Levy, S. MacCracken, P. Mastrandrea y L. White (eds.)]. (14991566). Cambridge: Cambridge University Press. Recuperado de https://www. ipcc.ch/pdf/assessment-report/ar5/wg2/ WGIIAR5-Chap27_FINAL.pdf 
Medioambiente. (Septiembre 13, 2017a). En el 2040, 119 municipios en riesgo muy alto por cambio climático. El Tiempo. [Vida]. Recuperado de https://www.eltiempo.com/vida/ medio-ambiente/como-el-cambio-climatico-esta-afectando-a-colombia-129862

Medioambiente. (Junio 13, 2017b). Estos son los planes de Colombia para enfrentar el cambio climático. El Tiempo. [Vida]. Recuperado de https://www.eltiempo. com/vida/medio-ambiente/politica-decolombia-para-enfrentar-el-cambio-climatico-98710

National Geographic. (Septiembre 5, 2010). ¿Qué es el calentamiento global? Recuperado de http://www.nationalgeographic. es/medio-ambiente/que-es-el-calentamiento-global

NASA ClimateKids. (2018). What is an urban heat island? Recuperado de https://climatekids.nasa.gov/heat-islands/

Oelze, S. y Romero-Castillo, E. (2012). "Ciudades resilientes", urbes del futuro. DW, Actualidad. Recuperado de https://www.dw.com/es/ciudades-resilientes-urbes-del-futuro/a-16253378

OMS. (Diciembre 17, 2017). Banco Mundial y OMS: la mitad del mundo carece de acceso a servicios de salud esenciales y los gastos en salud abocan aún hoy a la pobreza extrema a 100 millones de personas. Recuperado de http://www. who.int/es/news-room/detail/13-12-2017world-bank-and-who-half-the-world-lacksaccess-to-essential-health-services-100million-still-pushed-into-extreme-povertybecause-of-health-expenses
ONU. (s.f.). Our work in Latin America and the Caribbean. Recuperado de https:// www.unenvironment.org/regions/ latin-america-and-caribbean/ourwork-latin-america-and-caribbean

ONU-Habitat. (2011). Cities and Climate Change. London-Washington: Earthscan.

ONU-Habitat. (2017). Resiliencia urbana. Recuperado de https://es.unhabitat. org/resiliencia/

Pacala, S. y Socolow, R. (2004). Stabilization Wedges: Solving the Climate Problem for the Next 50 Years with Current Technologies (Vol. 305). Princeton, Nueva Jersey (USA): Princenton University.

Pardo, T. (Septiembre 16, 2017). Para el 2100, la temperatura del país será $2,4^{\circ} \mathrm{C}$ más alta. El Tiempo. [Vida]. Recuperado de https://www. eltiempo.com/vida/medio-ambiente/ temperatura-de-colombia-serados-grados-centigrados-masalta-para-el-2100-131260

PNUMA. (2015). Informe sobre la disparidad en las emisiones. Nairobi: Programa de las Naciones Unidas para el Medio Ambiente (PNUMA).

Pure New Zealand. (s.f.). Plantas y animales de Nueva Zelanda. Recuperado de https://www.newzealand.com/cl/ feature/new-zealand-flora-and-fauna/

RAE. (s.f.). Enclave de la Real Academia Española. Recuperado de http://dle. rae.es/srv/fetch?id=JvbcNEL 
República de Colombia. Minambiente. (2018a). Colombia avanza en busca de su resiliencia al cambio climático. Recuperado de http://www.minambiente.gov.co/index.php/noticias/3895colombia-avanza-en-busca-de-su-resiliencia-al-cambio-climatico

República de Colombia. Minambiente. (2018b). GasesEfectoInvernadero. Recuperado de http://www.minambiente. gov.co/index.php/component/content/ article?id=462: plantilla-cambio-climatico-18\#enlaces

República de Colombia. Minambiente. (2016). Plan Nacional de Adaptación al Cambio Climático. Bogotá, D.C.: Integra Producción y Logística.

Rodríguez, L. (2010). Efectos de los árboles sobre el viento en el medio urbano.

Módulo Arquitectura CUC, 9(1), 131-144. Recuperado de http://revistascientificas.cuc.edu.co/index.php/moduloarquitecturacuc/article/download/122/ pdf_53

Rodríguez, L. y Padilla, S. (2018). El urbanismo: ¿Cómo construir ciudades fértiles? En, S. Nail, Aliementar las ciudades. Territorio, actores, relaciones (117-156). Bogotá, D.C.: Universidad Externado.

Rodriguez, L., Hanrot, S., Dabat, M.-A. e Izard, J.-L. (2013). Influence of trees on the air temperature in outdoor spaces according to planting parameters: the case of the city of Aix-en-Provence in France. WIT Transactions on Ecology and the Environment, 173, 299-310.
Rodriguez, L., Hanrot, S., Dabat, M.-A. e Izard, J.-L. (2012). Variation des paramètres de plantation des arbres d'alignement dans un milieu urbain et son influence sur la température de l'air-Cas d'Aix-enProvence, France. Ambiances in action/ Ambiances en acte (s)-International Congress on Ambiances, 261-266.

Rodríguez, M. y Mance, H. (2009). Cambio climático: lo que está en juego. Bogotá, D.C.: Foro Nacional Ambiental. Recuperado de http://library.fes.de/pdf-files/ bueros/kolumbien/07216.pdf

Schuschny, A. (2014). Sostenibilidad y resiliencia urbana: aportes para su medición. En, Comisión Económica para América Latina y el Caribe (CEPALONU), Conversatorio: Evaluación de la sustentabilidad urbana Secretaria Distrital de Ambiente-ONU Habitat. [Presentación]. Recuperado de http:// oab2.ambientebogota.gov.co/apc-aafiles/57c59a889ca266ee6533c26f970 cb14a/resiliencia_urbana_y_sostenibilidad_andres_schuschny.pdf

UN Habitat y UNISDR. (2018). Progress on the Making Cities Sustainable and Resilient Action. UN Habitat. Recuperado de https://www.unisdr.org/files/5 8509_58509makingcitiessustainablea ndresi.pdf

Vogt, V. (Marzo 24, 2018). Para 2050 América habría perdido el $40 \%$ de su diversidad biológica. El Tiempo. Recuperado de http://www.eltiempo.com/colombia/ medellin/termino-de-ipbes-dejaevidencia-alarmante-sobre-biodiversidad-mundial-197612 
Lizeth Rodríguez Potes es doctora en Arquitectura, de la Universidad AixMarseille. Investigadora y docente de la Facultad de Arquitectura de la Universidad del Atlántico en Barranquilla, Colombia.
Kevin Rafael Therán Nieto es estudiante de IX semestre del programa de Arquitectura y Diseño de la facultad de Arquitectura de la Universidad de la Costa, CUC en Barranquilla, Colombia. Semillero de investigación del grupo ARUCO de la Facultad de Arquitectura y becado por el Programa Opción en la Universidad de la Costa, CUC. 